\title{
Apoio Popular à Integração Econômica Regional na América Latina'
}

\author{
Mitchell A. Seligson \\ Departamento de Ciência Política \\ University of Pittsburgh - EUA
}

\begin{abstract}
Resumo
Esquemas de integração econômica regional abundam na América Latina, mas muito pouco se sabe sobre o grau de apoio popular a esses programas. Agora que os regimes democráticos governam quase toda a América Latina, a opinião pública pode ter impacto considerável nas políticas nacionais. Este trabalho examina as atitudes em relação à integração econômica em dezessete países continentais latino-americanos com dados de entrevistas com mais de 18 mil pessoas. Os benefícios percebidos da integração e as percepções sobre a situação econômica pessoal e nacional aparecem como fatores importantes, assim como altos níveis educacionais, o apoio à democracia e o gênero. Dois novos achados são que uma opinião positiva sobre a União Européia e a satisfação com o funcionamento da democracia se ligam a um maior apoio à integração.
\end{abstract}

Palavras-chave: América Latina; integração econômica; democracia; opinião pública.

\section{Abstract}

Regional economic integration schemes abound in Latin America, yet very little is known about the degree of popular support for such programs. Now that democratic regimes rule in almost all of Latin America, public opinion can have an important impact on national policies. This paper examines the attitudes toward economic integration in 17 mainland Latin American countries with interview data from over 18,000 people. Perceived benefits of integration and perceptions of personal and national economic situation prove to be important factors, as are higher levels of education, support for democracy and gender. Two novel findings are that a positive opinion of the European Union along with satisfaction with the functioning of democracy are both linked to greater support for integration.

Key words: Latin America; economic integration; democracy; public opinion.

${ }^{1}$ Esta é uma versão ligeiramente revisada de trabalho publicado como Popular Support for Regional Economic Integration in Latin America, Journal of Latin American Studies 31 (1) 1999: 129-150. 
Embora a integração econômica de larga escala e de maior sucesso tenha surgido na Europa, desde o fim da Segunda Guerra Mundial as nações latino-americanas experimentaram numerosos programas de integração. O sucesso na América Latina tem sido muito mais limitado, porém, e esquemas outrora promissores como o Mercado Comum da América Central se desorganizaram como resultado de conflitos internacionais e levantes domésticos. De qualquer modo, a recente e rápida expansão do Mercosul, o grupo hoje dominante no chamado "Cone Sul" da América do Sul, e a revitalização tanto do Pacto Andino quanto do outrora moribundo Mercado Comum da América Central vem levando os otimistas a sugerir que a América Latina pode estar seguindo os passos integracionistas da Europa. A esperança dos que a apóiam é de que muitos dos ganhos econômicos que a Europa obteve como resultado da integração econômica podem ser também obtidos pela América Latina se ela desenvolver blocos de comércio regionais ou sub-regionais.

Que fatores podem promover (ou bloquear) o apoio à integração entre os governos da América Latina? Durante os primeiros trinta anos após a Segunda Guerra, os esforços integracionistas na América Latina eram promovidos quase exclusivamente por pequenos grupos de tecnocratas e das elites econômicas, que eram capazes de funcionar sem dar atenção à oposição pública (especialmente operária) potencial, uma vez que nessa época a maior parte da região estava submetida a regimes autoritários. Ao fim dos anos 80 , porém, a América Latina tinha abandonado (pelo menos temporariamente) seu passado autoritário. Hoje, com exceção de Cuba, toda a região é governada por regimes eleitos, mesmo que a profundidade e estabilidade da democracia em vários países sejam uma questão ainda aberta.

Este trabalho examina o apoio e a oposição popular à integração econômica regional na América Latina. A probabilidade de que os governos latino-americanos avancem no projeto integracionista ou voltem-lhe as costas depende hoje muito mais da opinião pública que no passado autoritário. Nas democracias, a opinião pública conta muito, e uma forte oposição à integração pode significar o fim do movimento regionalista na América Latina. Os sindicatos, por exemplo, podem se opor a medidas integracionistas, como muitos de fato o fizeram nos Estados Unidos durante os debates sobre o NAFTA. A oposição pública ao NAFTA foi a principal base utilizada por seus oponentes no Congresso para votar contra o tratado, o que quase o levou à derrota. Além disso, a opinião pública, outrora pensada como relevante nas democracias apenas em questões domésticas, tem surgido em muitas pesquisas acadêmicas como de grande impacto em questões-chave de política externa. ${ }^{2}$ Ademais, a opinião pública que se acreditava quase aleatória em questões de política externa tem aparecido como

\footnotetext{
${ }^{2}$ Para uma boa revisão da ligação entre opinião pública e políticas públicas, ver Lawrence R. Jacobs e Robert Y. Shapiro, Studying Substantive Democracy, PS: Political Science and Politics 27 (1) 1994. Para um estudo que mostra o efeito direto da opinião pública norte-americana em política externa, ver Bruce Russet, Thomas Hartley e Shoon Murray, The End of the Cold War, Attitude Change and the Politics of Defense Spending, PS: Politics and Society 27 (1) 1994.
} 
coerentemente estruturada. Tem sido demonstrado que essa estruturação existe também na América Latina. ${ }^{3}$

No caso da integração européia, foi desenvolvido um extenso conjunto de pesquisas sobre a importância da opinião pública para o avanço do programa. ${ }^{4}$ Acreditava-se que as atitudes do público eram irrelevantes para as complexas questões técnicas da integração européia, mas a rejeição dos eleitores dinamarqueses ao Tratado de Maastricht em 1992 mostrou que, sem apoio público, o progresso na integração poderia ser suspenso ou mesmo revertido. Com base em extenso estudo de dados de opinião pública coletados na União Européia por mais de dez anos, Richard Eichenberg e Russell J. Dalton concluem que "quando vistos no contexto da Europa pós-debate de Maastricht, nossos resultados sugerem que a ligação entre o consenso dos cidadãos em questões domésticas e o conteúdo dos acordos internacionais se tornará ainda mais estreita". 5

Enquanto a opinião dos europeus sobre a União Européia tem sido extensamente estudada, muito menos se sabe sobre outros esquemas de integração regional. Com exceção do NAFTA, o papel da opinião pública nos esquemas econômicos regionais na América Latina não tem sido estudado. A pouca pesquisa publicada cobriu apenas países individuais ou pequenos grupos, como a integração da América Central. ${ }^{6}$ Muito recentemente, porém, foi disponibilizada uma nova fonte de dados que nos permite um exame cuidadoso do modo como os latino-americanos pensam sobre a integração econômica. O Latinobarômetro, seguindo o modelo do Eurobarômetro sobre o qual se basearam muitas das pesquisas sobre integração, cobre todos os países continentais, do México até a ponta da América do Sul, com exceção do Suriname e das Guianas. ${ }^{7} \quad 0$ Latinobarômetro de 1996 envolveu mais de 18 mil entrevistas em 17 países. Na maioria dos países, as amostras ficaram por volta de 1.000 entrevistados, exceto na Venezuela, onde foram 1.500, e Bolívia e Paraguai, onde foram menores. ${ }^{8}$ São em geral amostras

\footnotetext{
${ }^{3}$ John Hurwitz, Mark Peffley e Mitchell A. Seligson, Foreign Policy Belief Systems in Comparative Perspective: The United States and Costa Rica, International Studies Quarterly 371993.

${ }^{4}$ Robert J. Shepherd, Public Opinion and European Integration, Westmead, England, Saxon House, 1975; Ronald Inglehart, Long Term Trends in Mass Support for European Unification, Government and Opposition 12 (2) 1977: 150177; Inglehart, Culture Shift in Advanced Industrial Society, Princeton, Princeton University Press, 1990.

${ }^{5}$ Richard Eichenberg e Russell J. Dalton, Europeans and the European Community: The Dynamics of Public Support for European Integration, International Organization 47 1993: 532.

${ }^{6}$ Mitchell A. Seligson e Ricardo Córdova, Integration and Disintegration in Central America: From 1950-1990, in Changing Boundaries in the Americas: New Perspectives on the US-Mexican, Central American and South American Borders, org. Lawrence A. Herzog, San Diego, Center for US-Mexican Studies, 1992: 151-166; e Mitchell A. Seligson, Actitudes de la Población Centroamericana Frente a la Integración Política y Económica, Anuário de Estudios Centroamericanos 19 (2) 1993a: 7-24.

${ }^{7}$ Os dados do Latinobarômetro de 1996 foram tornados disponíveis pela União Européia, via o Centro de Investigación, Promoción y Cooperación Internacional da Espanha e do Programa de Desenvolvimento das Nações Unidas na América Central. Os arquivos de dados são do Banco Inter-Americano de Desenvolvimento. N. do E.: Sobre as amostras ver Opinião Pública, Vol. VI, $n^{\circ} 1$, ENCARTE.

${ }^{8} \mathrm{O}$ resumo publicado sobre a América Central apresenta pequena variação de 2-3 casos para Costa Rica, Nicarágua e Panamá. A variação resulta de codificação ambígua do país num total de 8 entrevistas das mais de 18.000 realizadas. Ver PNUD (Programa de las Naciones Unidas para el Desarrollo), Desarrollo Humano Sostenible, Informe Latinobarómetro: Consolidado de Centroamérica, Proyecto CAM 96.001, San José, Costa Rica, 1996. Para uma discussão geral de alguns
} 
probabilísticas urbanas. Para o arquivo de dados como um todo, $49 \%$ dos entrevistados foram homens e $51 \%$, mulheres.

$\mathrm{Na}$ análise que segue, os dados dos 17 países foram ponderados para refletir os diferentes tamanhos das populações dos países de que as amostras foram obtidas, e então reunidos novamente de modo a que se possa examinar as tendências para a América Latina como um todo. ${ }^{9} \quad$ Análises dos dados europeus sobre a integração seguiram o mesmo caminho, reunindo os dados de todos os países, ou olhando os membros originais da Comunidade Européia e então o número ampliado (corrente) de membros da União Européia. Como não há hoje mercado que atinja toda a América Latina, outra abordagem seria comparar grupos regionais dentro da região (p. ex., Pacto Andino, Mercosul, Mercado Comum Centroamericano etc.) e um outro ainda, mais voltado ao nível micro, seria olhar para cada um dos 17 países isoladamente. Esta não é a estratégia adotada neste trabalho, pois preferimos olhar para as tendências para o conjunto da América Latina. No futuro, os pesquisadores podem querer ver mais de perto as diferenças entre os acordos comerciais ou entre os países. É importante notar desde o começo, no entanto, que o apoio à integração na América Latina não é função do nível relativo de desenvolvimento econômico dos países envolvidos. A inclusão dos dados de Produto Interno Bruto (como mostramos adiante) não altera os padrões gerais apresentados.

Este trabalho segue a tradição analítica do estudo de dados de opinião pública na União Européia, como apresentado pelo programa Beliefs in Government, da European Science Foundation. Um volume de 1995 da Oxford University Press resume o que se sabe sobre a opinião pública no caso europeu. ${ }^{10}$ Esta análise começa com opiniões e 'não-opiniões', isto é, a medida em que os latino-americanos têm ou não posição sobre a integração econômica. Passa então a examinar o apoio/oposição à integração e a percepção dos benefícios recebidos dos vários acordos comerciais regionais até o presente. A análise dos dados busca os fatores relacionados ao apoio à integração entre os latino-americanos e conclui com uma análise multivariada desses fatores.

\section{Opiniões e Não-Opiniões}

Antes de examinar as opiniões sobre a integração na América Latina, é necessário separar aqueles que têm uma opinião sobre o assunto dos que não têm. Se, por exemplo, poucos latino-americanos tivessem qualquer opinião sobre o tema, seria

dos dados de survey para a América Central, ver Proyecto de Governabilidad para Centroamérica, Eı Desafío Democrático: Reflexiones de las Sociedades Centroamericanas ante el Resultado del Latinobarómetro 1996, PNUD, San José, Costa Rica, 1997; e Marta Lagos, Latin America's Smiling Mask, Journal of Democracy 8 (3) 1997: 125-138.

${ }^{9}$ Os dados de população são estimativas para 1995 do Banco Mundial, World Development Report, 1989, Washington, D.C., Oxford University Press, 1997: 214-215.

${ }^{10}$ Oskar Niedermayer e Richard Sinott (orgs) Public Opinion and Internationalized Governance, Beliefs in Government, vol. II, Oxford, Oxford University Press, 1995. 
uma distorção apresentar as porcentagens da pequena minoria com opiniões. Podemos estimar a falta de opiniões sobre a integração latino-americana utilizando uma das duas questões-chave formuladas no Latinobarômetro. A todos os entrevistados foi perguntado: "Em geral, você é a favor ou contra a integração econômica dos países da América Latina, mesmo que isso possa significar alguns custos ou sacrifícios para [preencher com o nome do país do survey]". O item pode parecer viesado, uma vez que enfatiza os custos da integração sem referir eventuais benefícios. No entanto, pesquisa prévia com grupos focais mostrou que, a menos que os custos fossem mencionados, os entrevistados responderiam rápida e positivamente a questões de integração econômica, sem pensar em todas suas implicações. Isso seria equivalente a perguntar a um entrevistado, "você gostaria de ganhar mais dinheiro?" sem observar que, para isso, ele teria que trabalhar mais horas por semana. Quando os possíveis custos são mencionados obtém-se uma estimativa mais realista do apoio. A porcentagem de entrevistados em cada país que não tinham opinião sobre essa questão é mostrada na Figura 1. Para a amostra como um todo, $17,7 \%$ dos entrevistados não tinham opinião (pró ou contra) sobre a integração econômica da América Latina. Como a figura mostra, na América Central, com exceção de Panamá e Nicarágua, a não-opinião chega de um terço a dois quintos das amostras.

FIGURA 1

Não-Opinião sobre a Integração Econômica na América Latina

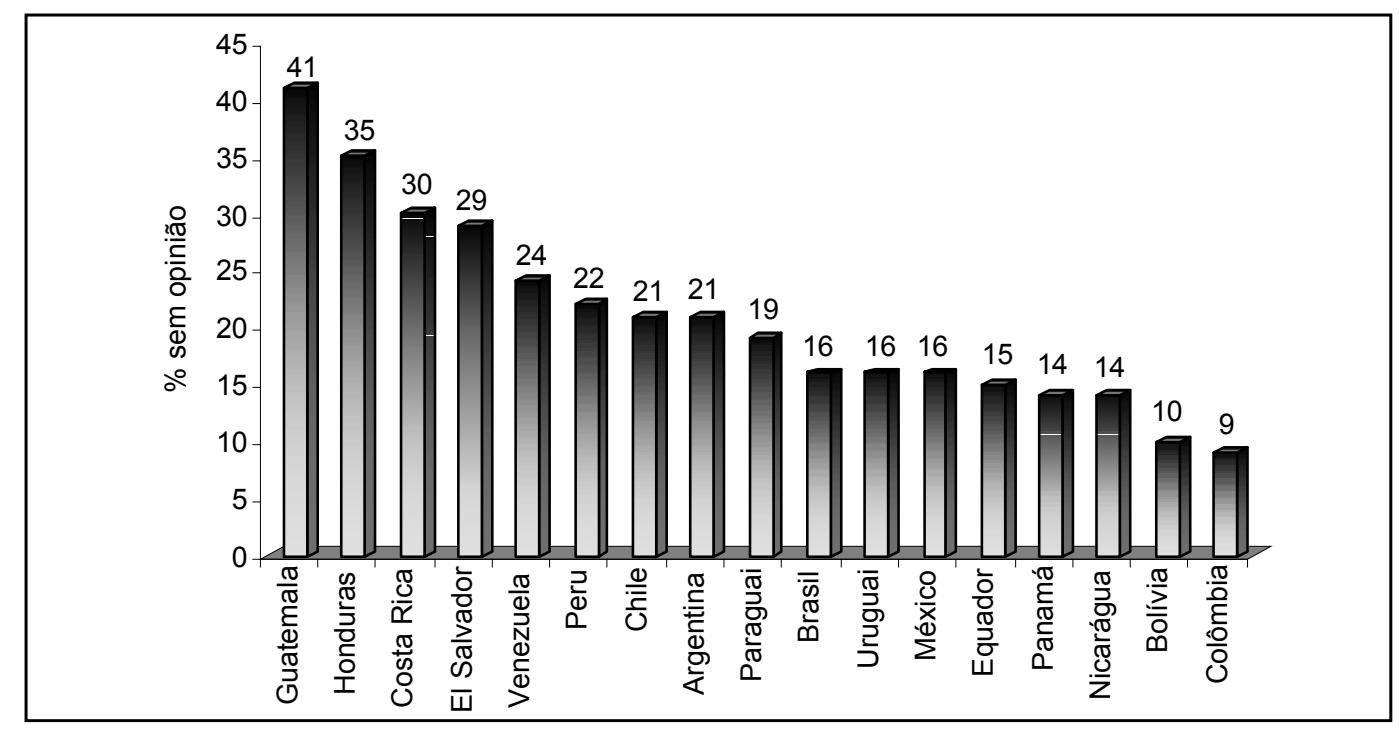


Como diferem os que têm opiniões dos que não têm quanto à questão da integração regional na América Latina? Uma análise de regressão logística foi realizada no conjunto dos dados comparando os dois grupos. Os resultados aparecem na Tabela 1. Como aconteceu no caso dos surveys europeus sobre integração, os principais determinantes da não-opinião na América Latina são fatores socioeconômicos e demográficos. Especificamente, os que não expressaram qualquer opinião contra ou a favor da integração econômica latino-americana eram, com probabilidade significativamente maior, mais velhos, mais pobres, menos escolarizados, menos atentos a noticiário político e do sexo feminino.

TABELA 1

Preditores da Não-Opinião: Resultados da Regressão Logística

\begin{tabular}{|l|l|l|l|l|l|}
\hline Variável & B & E.P & GL & Sig. & $R$ \\
\hline Atenção à política & -.42 & .005 & 1 & $<.001$ & -.13 \\
\hline Anos de escolaridade &.-08 & .001 & 1 & $<.001$ & -.11 \\
\hline Sexo $^{\text {a }}$ & .47 & .008 & 1 & $<.001$ & -.09 \\
\hline Riqueza & & & & \\
\hline Idade & -.01 & .001 & 1 & $<.001$ & -.11 \\
\hline Constante & .01 & .001 & 1 & $<.001$ & .01 \\
\hline $\begin{array}{l}\text { a Sexo codificado 1=masculino, 2=feminino } \\
\text { b Riqueza medida por um índice de 13 itens propredade de bens durá }\end{array}$ & .96 & .019 & 1 & $<.001$ & \\
\hline
\end{tabular}

${ }^{\mathrm{b}}$ Riqueza medida por um índice de 13 itens de propriedade de bens duráveis.

Há alguma variação no padrão de não-respostas por país. Por exemplo, na Figura 2 as respostas foram separadas por gênero. Em todos os países, exceto a Guatemala, as mulheres têm significativamente menos probabilidade de expressar opiniões do que os homens. Na Europa, o hiato de gênero também existe, mas é mais estreito, na média menos de $6 \% .^{11}$

11 Bernhard Wessels, Development of Support: Diffusion or Demographic Replacement? In Public Opinion and International Governance, org. Oskar Niedermayer e Richard Sinott, Oxford, Oxford University Press, 1995. 
FIGURA 2

Não-Opinião sobre a Integração Econômica na América Latina

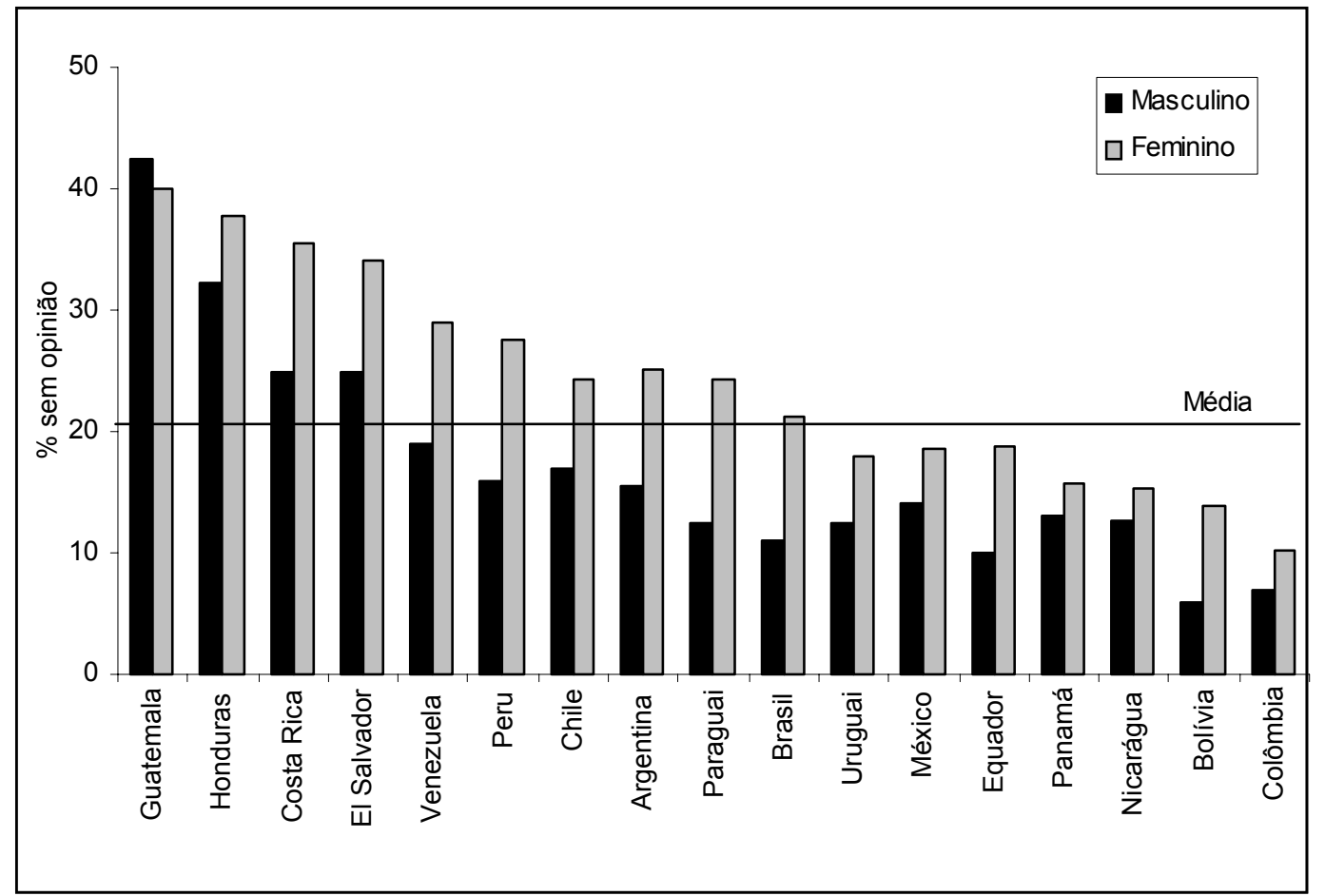

As outras variáveis socioeconômicas e demográficas mostradas na análise de regressão são preditores significativos em cada país, ainda que a força da associação varie de caso a caso. Por exemplo, a Figura 3 mostra que em todos os países no survey aqueles que tinham opinião sobre a integração econômica apresentavam nível educacional (medido por anos na escola) médio mais alto que os que não tinham opinião.

O Latinobarômetro utilizou uma segunda questão para aferir a opinião sobre a integração regional perguntando: "levando tudo em consideração, você diria que [preencher o país] se beneficiou muito, o bastante, ou não se beneficiou por pertencer ao [Pacto Andino, Mercosul, etc.]". A análise das respostas a esse item forma um componente dos resultados apresentados abaixo, mas os padrões de não-resposta e correlatos são semelhantes aos do item que refere apoio/oposição à integração analisado acima, e por isso não serão repetidos aqui. ${ }^{12}$ Em geral, portanto, os padrões de não-

\footnotetext{
${ }^{12}$ Existe ainda uma terceira série que mede a opinião/não-opinião no Latinobarômetro. Essa série, porém, pergunta aos entrevistados sobre cada bloco comercial específico, Mercosul, NAFTA e Pacto Andino. A análise dessas questões mostra que o conhecimento do pacto específico é muito maior nas amostras dos países que fazem parte do pacto, o que não é surpreendente. Infelizmente, não foi feita qualquer pergunta sobre o Mercado Comum Centroamericano, excluindo assim
} 
opinião sobre a integração econômica são semelhantes em toda a América Latina, e são uma função preditiva de características socioeconômicas e demográficas.

FIGURA 3

Não-Opinião sobre a Integração Econômica na América Latina, segundo Educação

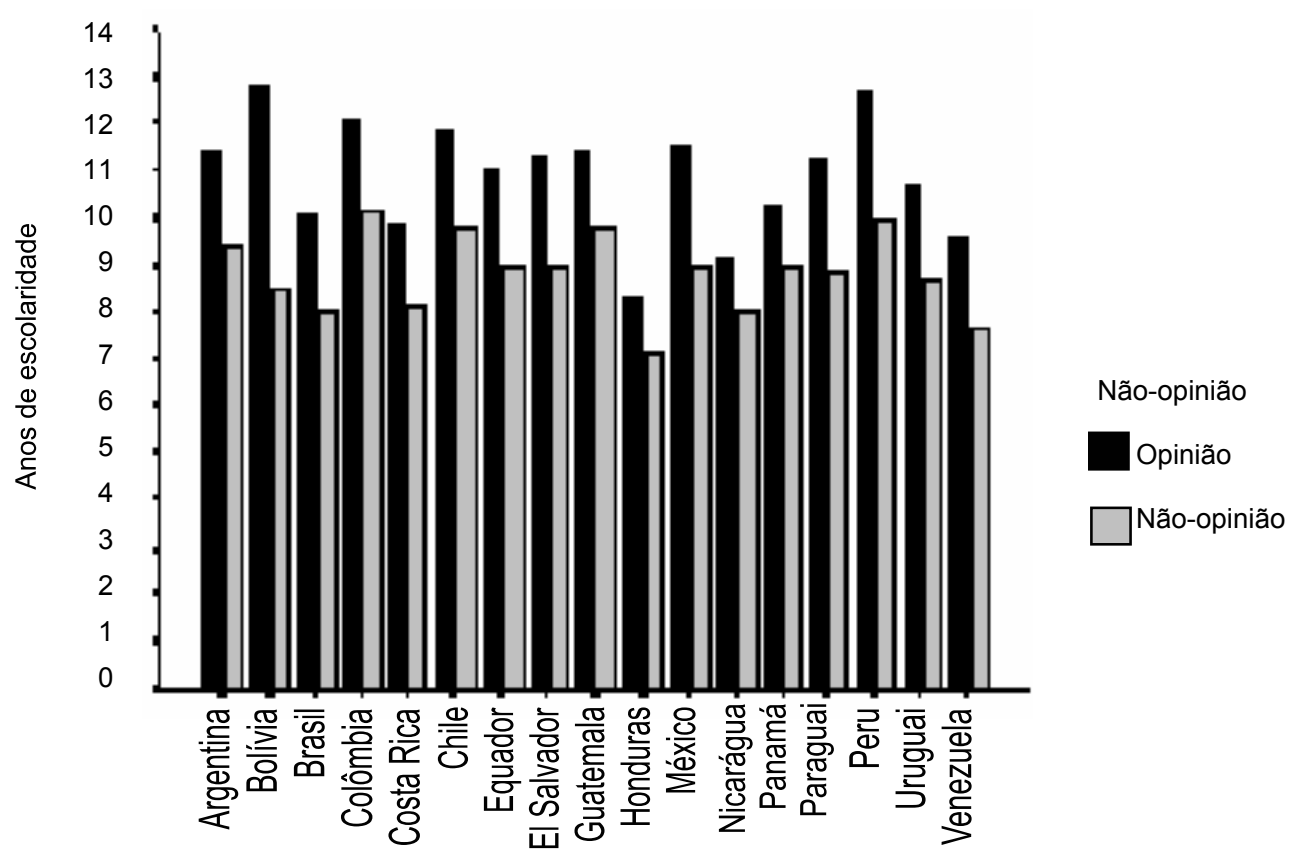

aqueles seis países da análise. A fim de evitar apresentar os resultados para cada bloco comercial e para cada conjunto de países que pertencem àquele bloco essas variáveis não são analisadas aqui. 


\section{Apoio e Benefícios da Integração Regional na América Latina}

\section{Apoio à Integração}

\section{FIGURA 4}

Apoio à Integração na América Latina

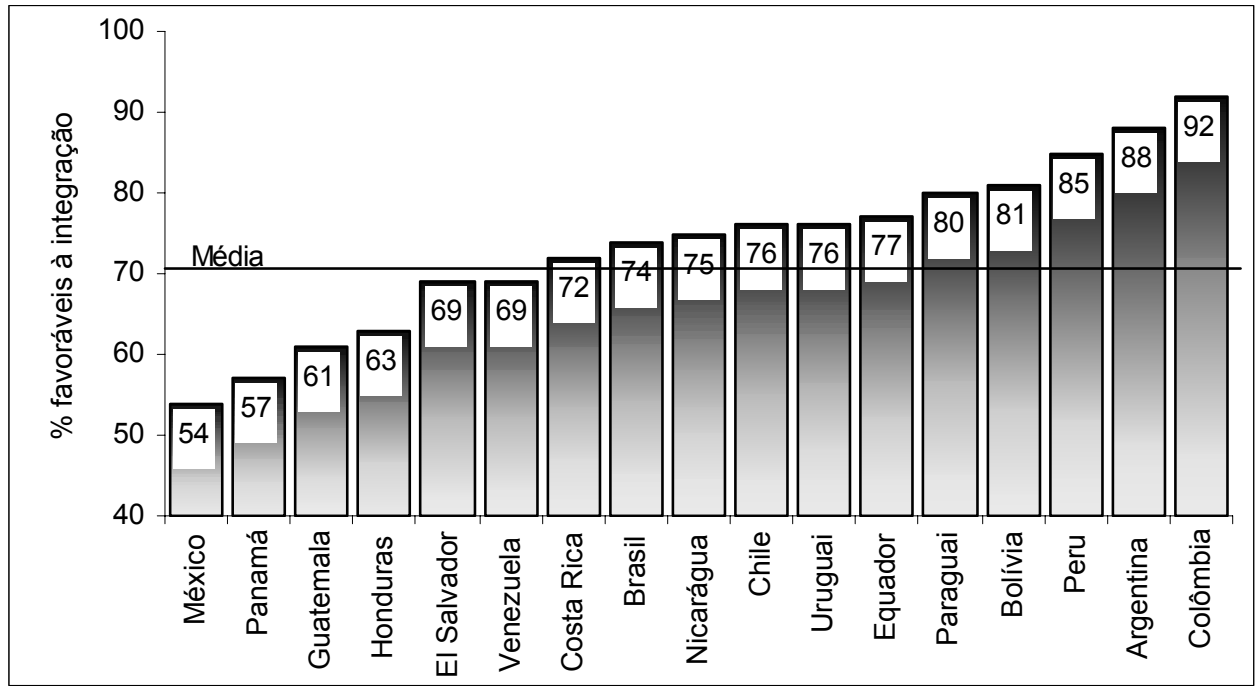

Obs.:Inclui apenas os que têm opinião

Este trabalho mostra que, na média, mais de quatro de cada cinco latinoamericanos têm uma opinião sobre a integração econômica. Para esses que tinham opinião na onda de surveys de 1996, qual o nível de apoio à integração econômica? Para responder a essa questão, as "não-opiniões" são excluídas da base de dados. A resposta é apresentada na Figura 4. Com exceção de quatro países, dois terços da amostra apóiam a integração, e em nove dos 17 países, três quartos ou mais a apóiam. O padrão emergente mostra que o apoio é mais fraco no México e na América Central, e mais forte na América do Sul, especialmente no Paraguai, Bolívia, Argentina e Colômbia.

Parece haver uma dimensão "norte-sul" na determinação do apoio à integração regional na América Latina. Pode muito bem ser que os Mexicanos e Centro-americanos estejam mais interessados em integrar-se à América do Norte que à do Sul. Infelizmente, o questionário do Latinobarômetro não contrasta NAFTA e programas de integração latino-americanos, de modo que não é possível aprofundar a questão. É sugestivo, porém, que, ainda que o Chile tenha sido indicado como o próximo país a integrar a NAFTA (dependendo, é claro, de apoio de todos os membros correntes, o que não está garantido no momento em que escrevo), os chilenos apóiam a integração econômica com a América Latina em medida muito maior que os Mexicanos e muitos Centro-Americanos. 
A divisão norte-sul se torna ainda mais evidente quando a não-opinião é introduzida na análise. A Tabela 2 mostra que, para todos os países, quando a nãoopinião é incluída na análise, o apoio à integração declina. Na área norte da América Latina, apenas na Nicarágua e na Costa Rica há maiorias a favor da integração. Mesmo nesses países, porém, como observado acima, os que apóiam a integração superam em números os que se opõem a ela, enquanto que na América do Sul a maioria apóia a integração regional mesmo incluída a não-opinião.

\section{TABELA 2}

\section{Apoio e Oposição à Integração}

\begin{tabular}{r|rrr} 
País & Oposição & Apoio & Total \\
\hline Argentina & $12.2 \%$ & $77.8 \%$ & $100.0 \%$ \\
Bolívia & $19.5 \%$ & $80.5 \%$ & $100.0 \%$ \\
Brasil & $26.3 \%$ & $73.7 \%$ & $100.0 \%$ \\
Colômbia & $8.4 \%$ & $91.6 \%$ & $100.0 \%$ \\
Costa Rica & $28.4 \%$ & $71.6 \%$ & $100.0 \%$ \\
Chile & $24.2 \%$ & $75.8 \%$ & $100.0 \%$ \\
Equador & $22.5 \%$ & $77.5 \%$ & $100.0 \%$ \\
El Salvador & $30.9 \%$ & $69.1 \%$ & $100.0 \%$ \\
Guatemala & $38.7 \%$ & $61.3 \%$ & $100.0 \%$ \\
Honduras & $36.7 \%$ & $63.3 \%$ & $100.0 \%$ \\
México & $46.4 \%$ & $53.6 \%$ & $100.0 \%$ \\
Nicarágua & $25.4 \%$ & $74.6 \%$ & $100.0 \%$ \\
Panamá & $42.6 \%$ & $57.4 \%$ & $100.0 \%$ \\
Paraguai & $19.5 \%$ & $80.5 \%$ & $100.0 \%$ \\
Peru & $15.2 \%$ & $84.8 \%$ & $100.0 \%$ \\
Uruguai & $24.1 \%$ & $75.9 \%$ & $100.0 \%$ \\
Venezuela & $30.5 \%$ & $69.5 \%$ & $100.0 \%$ \\
Total & $28.8 \%$ & $71.2 \%$ & $100.0 \%$
\end{tabular}

No geral, portanto, os formadores de políticas que querem a integração econômica regional podem confiar em que todos os países a maioria dos que têm opinião a apóiam, e na maioria dos países apenas um quinto da população se opõe à integração econômica. Apenas no México e no Panamá mais de um terço da população se opõe à integração regional. 


\section{Benefícios da Integração}

O apoio à integração é importante, é claro, mas os cidadãos querem ver as vantagens dessa política. Qual é a percepção dos benefícios da integração regional na América Latina de hoje? Em que medida acreditam os latino-americanos que seus esquemas comerciais regionais atuais (Pacto Andino, Mercosul, Mercado Comum Centroamericano, etc.) têm sido benéficos? A Figura 5 apresenta um padrão muito diferente daquele que resultou da análise do apoio/oposição à integração econômica. Com exceção dos colombianos, que não apenas apresentavam o mais baixo nível de nãoopiniões, mas também exibiam o mais alto nível de apoio, os benefícios advindos da integração são vistos, na média, como apenas modestos. A maioria dos países se agrupa muito próxima da média para todos os países (55,2 na escala de 100 pontos utilizada para apresentar esse item), e apenas quatro países (Paraguai, México, Peru e Uruguai) caem ligeiramente. Além disso, embora não esteja apresentado na Figura 5, para a amostra como um todo, a não-opinião é mais ampla, indo de aproximadamente um quinto dos entrevistados na questão sobre apoio à integração para aproximadamente um quarto dos entrevistados na questão dos benefícios.

\section{FIGURA 5}

Benefícios da Integração (entre os que têm opinião)

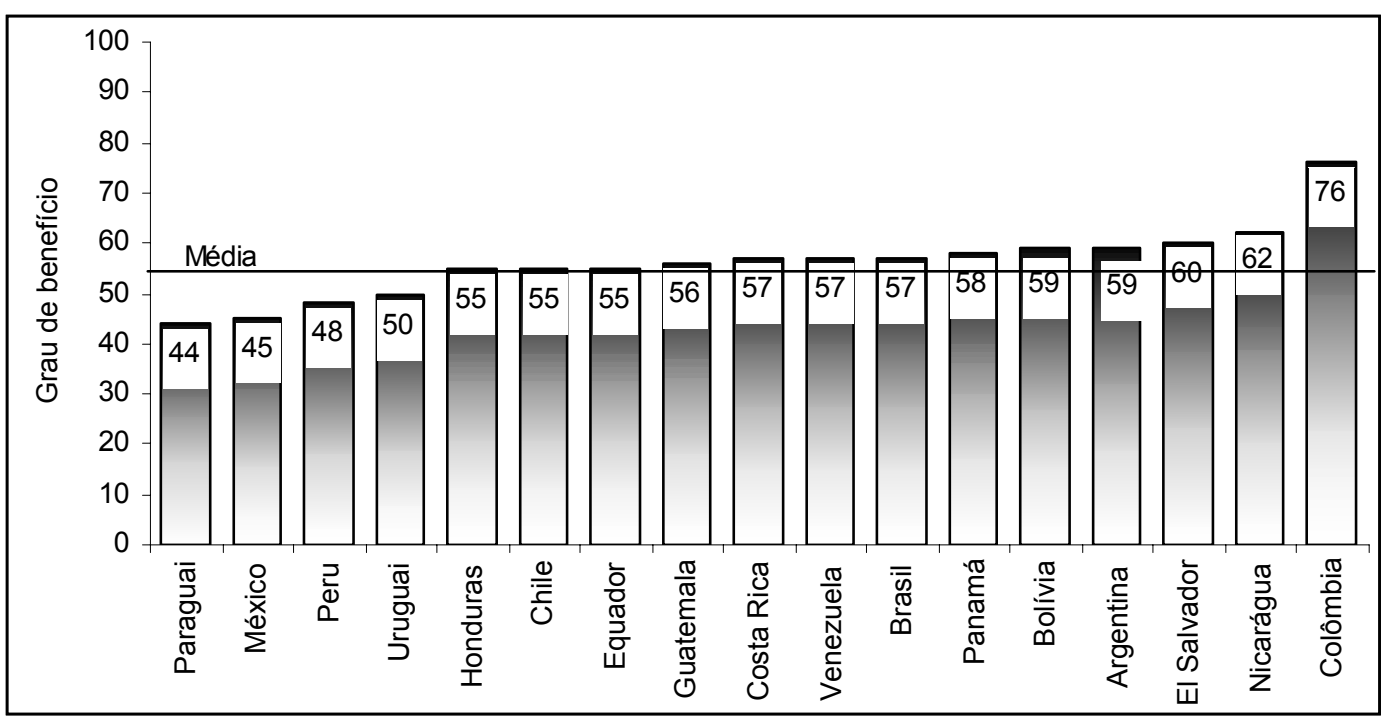

Escala: $\mathrm{Nada}=0 ; \mathrm{Um}$ pouco $=33 ;$ Suficientemente $=66 ;$ Muito $=100$ 
Combinando a informação dos itens analisados até aqui, podemos chegar a duas conclusões. Primeiro, existe forte apoio geral à integração regional latino-americana. Segundo, os benefícios dos esquemas de integração regional existentes são percebidos como apenas modestos, com exceção da Colômbia, onde são percebidos como maiores. O quê explica a variação no apoio à integração econômica na América Latina? Pode-se supor que é uma função do grau de desenvolvimento industrial de cada país, uma vez que o comércio gerado pelos esquemas de integração regional na América Latina emergiu no setor industrial. Mas, quando o desenvolvimento econômico ao nível nacional é examinado como preditor do apoio, não aparece associação significativa. ${ }^{13}$ Ademais, não há padrão que ligue as exportações (ou exportações per capita) a atitudes favoráveis à integração econômica regional. Para explicar a variação dos níveis de apoio, devemos olhar para fatores ao nível individual, o que apresento a seguir.

\section{Preditores do Apoio à Integração Econômica}

\section{Questões de "Carteira"}

Pesquisas mostraram que os principais determinantes do apoio à integração européia são as "questões de carteira". ${ }^{14} \mathrm{O}$ mais forte preditor atitudinal do apoio à integração européia é a medida em que os entrevistados sentem que o movimento de integração foi economicamente positivo para seu país. ${ }^{15}$ Além disso, aqueles que sentem que a economia nacional vai bem e que pessoalmente estão bem economicamente, apóiam mais a integração. Ainda que a experiência com a integração econômica na América Latina seja mais recente e limitada que no caso europeu, os padrões ao nível individual espelham de muito perto os europeus.

O impacto da crença de que o país se beneficia dos acordos comerciais regionais sobre o apoio à integração latino-americana aparece na Figura 6 . A relação é obviamente muito forte, e se mantém tanto para homens quanto para mulheres. Entre os latino-americanos que acreditam que os acordos comerciais regionais existentes não trazem benefício a seus países, menos de dois quintos apóiam a integração econômica latino-americana, enquanto que entre aqueles que acreditam que seus países se

\footnotetext{
${ }^{13}$ O desenvolvimento econômico foi medido pelo PIB per capita dito "real" para 1995, calculado pelo Banco Mundial. O PIB real é baseado na paridade de poder de compra e não por taxas de câmbio. Ver Banco Mundial, World Development Report, 1997, Washington, D.C., Oxford University Press, 1997.

${ }^{14}$ Para uma análise ampla, ver Richard Eichenberg e Russell J. Dalton, op. Cit. São feitas distinções entre as chamadas questões "sociotrópicas" e as "de carteira", as primeiras ligadas ao estado geral da economia e as últimas às questões econômicas pessoais. Análise dos dados do Latinobarômetro descobre que os dois conjuntos de questões econômicas têm impacto no apoio à integração, com diferenças relativamente pequenas entre eles. Pesquisadores interessados nessa distinção poderiam subdividir os itens na escala "de carteira" aqui utilizada.

15 Ver Charles Lyon e Jeffery J. Mondak Anke Grosskopf, Economic Perceptions and Mass Support for European Integration: Exploring the Dimensions of Sociotropic Behavior, trabalho apresentado na reunião annual da Midwest Political Science Association, Chicago, 1997.
} 
beneficiam muito, mais de $80 \%$ apóiam a integração. O apoio feminino à integração é virtualmente idêntico ao masculino na amostra, exceto nos níveis mais altos da variável benefícios, onde o apoio entre as mulheres é ligeiramente mais baixo.

\section{FIGURA 6}

Apoio à Integração Regional e Benefícios Percebidos dos Acordos Regionais

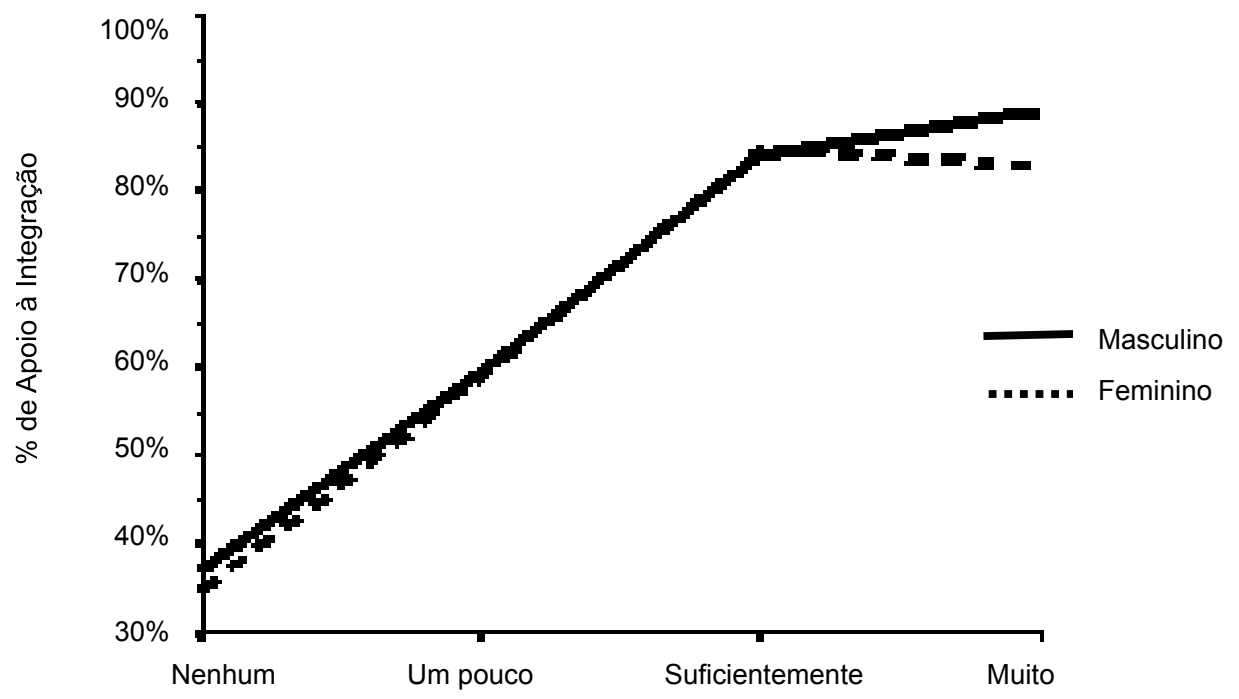

Os latino-americanos não apenas vinculam sua percepção sobre os benefícios econômicos dos acordos regionais ao seu apoio à integração regional, mas também à sua percepção das questões econômicas mais amplas. O survey aplicou uma série de perguntas em relação à percepção do entrevistado sobre a percepção de sua situação econômica pessoal e da do país. Uma relação direta e linear é encontrada para as variáveis que medem a percepção do futuro da economia nacional e a da situação atual e esperada da situação econômica do entrevistado. A relação entre essas variáveis, combinadas num índice, é apresentada na Figura $7 .{ }^{16}$ Embora os resultados mostrem uma clara e forte relação entre a percepção dos latino-americanos sobre a situação econômica de suas nações e a sua própria e o apoio à integração, também fica claro a partir da Figura 7 que, mesmo entre os mais pessimistas sobre a economia, dois terços ainda apóiam a integração. De qualquer modo, encontra-se aqui padrão idêntico ao

\footnotetext{
${ }^{16} \mathrm{O}$ índice compreende quatro variáveis: 1) percepção da situação econômica corrente do país em comparação com o ano anterior, 2) percepção da situação econômica no próximo ano, 3) percepção da situação familiar do entrevistado no próximo ano, 4) nível de temor em relação ao desemprego no futuro. O índice geral tem uma confiabilidade Alfa de 0,6 e produz apenas um fator numa análise de componentes principais. $\mathrm{O}$ item menos relacionado aos outros três é o medo do desemprego pessoal. Quando esse item é excluído, o Alfa sobe para 0,65. As respostas a cada item são aqui recodificadas numa base 0-100 para dar-lhes uma amplitude equivalente, e a soma é dividida por 4. Uma análise dos itens comparando preocupações retrospectivas e prospectivas não produz mudanças substanciais nos resultados.
} 
europeu, ou seja, que o apoio à integração é altamente contingente a questões econômicas "de carteira". Em países em que a economia declina deve-se esperar apoio declinante à integração. Da mesma forma, se o próprio processo de integração produz recompensas, e a economia cresce, também é possível esperar crescimento do apoio à integração.

\section{FIGURA 7}

Percepção sobre a Economia e Apoio à Integração

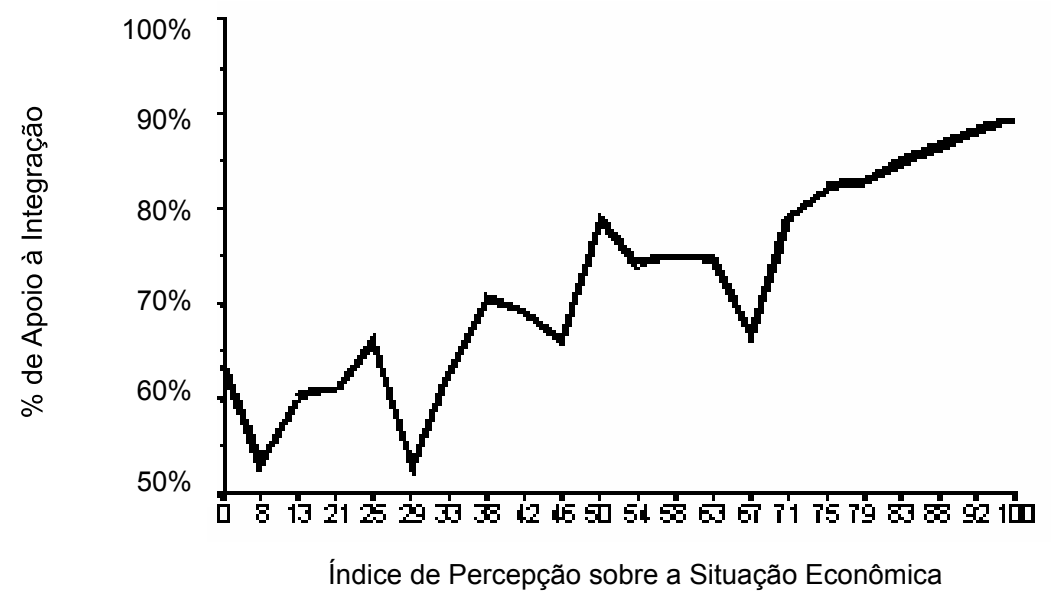

Fatores Socioeconômicos e Demográficos

Questões imediatas "de carteira" têm seu impacto no apoio à integração, mas fatores socioeconômicos e demográficos subjacentes também desempenham um papel. $\mathrm{Na}$ Europa, os mais escolarizados, os que têm profissão e os homens apóiam mais a integração que os menos escolarizados, os trabalhadores manuais e as mulheres. Já foi apontado que o gênero desempenha um papel na não-opinião nos dados latinoamericanos, e, nesta seção, esse fator e fatores socioeconômicos são analisados. ${ }^{17}$

Para examinar de maneira apropriada o papel do gênero no apoio à integração econômica, é necessário controlar a educação, pois os dados mostram que os homens têm significativamente maior escolaridade que as mulheres, ainda que a diferença não

\footnotetext{
${ }^{17}$ Exame da idade não encontrou relações nos dados. Na análise dos dados europeus, foram feitos diversos estudos sobre coortes de idade no tempo, mas como o Latinobarômetro ainda não oferece dados temporais, essa análise não pode ser feita aqui.
} 
seja grande em termos absolutos. A Figura 8 mostra a relação entre gênero e apoio à integração econômica latino-americana, controlada a educação. Dois achados emergem dessa análise. Primeiro, a educação tem papel importante na determinação do apoio à integração econômica latino-americana; entre os analfabetos, o apoio fica em torno de $60 \%$, enquanto que os que tem grau universitário o apoio é de aproximadamente $80 \%$. Segundo, o hiato de gênero se amplia entre os que têm educação secundária ou mais, mas entre os analfabetos, as mulheres exibem maior apoio que os homens. No todo, porém, o hiato não é amplo, e a educação claramente explica mais da diferença em apoio que o gênero.

\section{FIGURA 8}

Gênero e Apoio à Integração, controlada po Educação

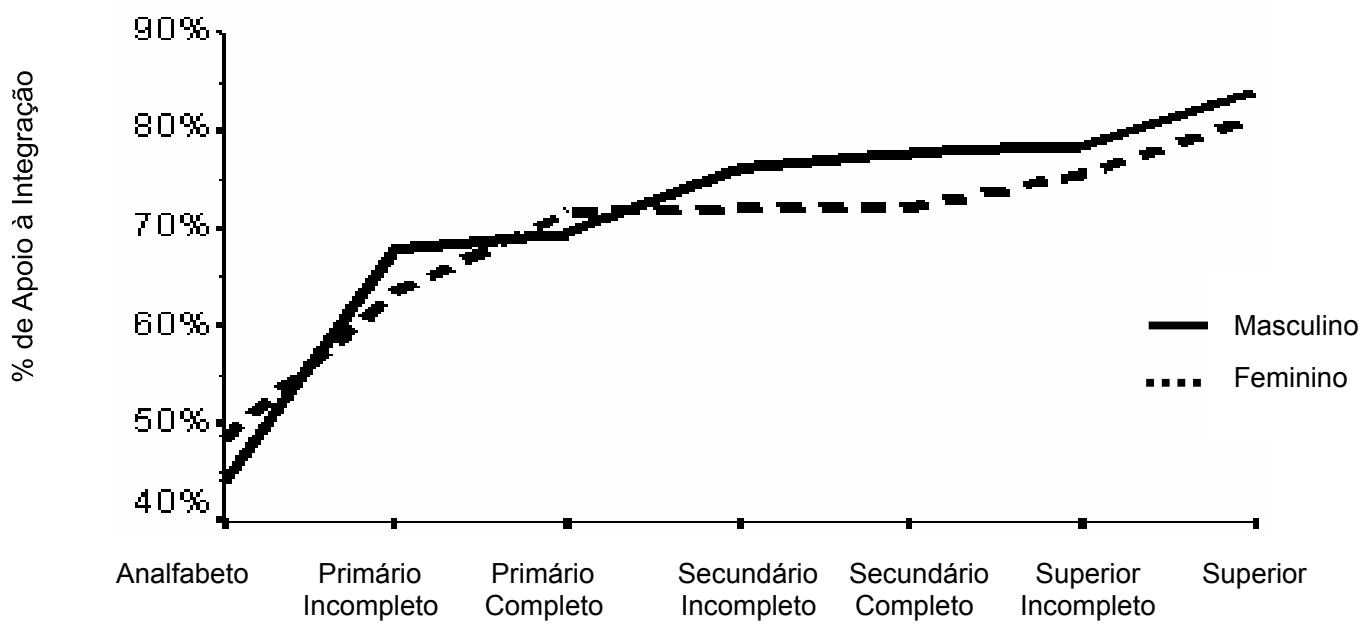


FIGURA 9

Ocupação e Apoio à Integração

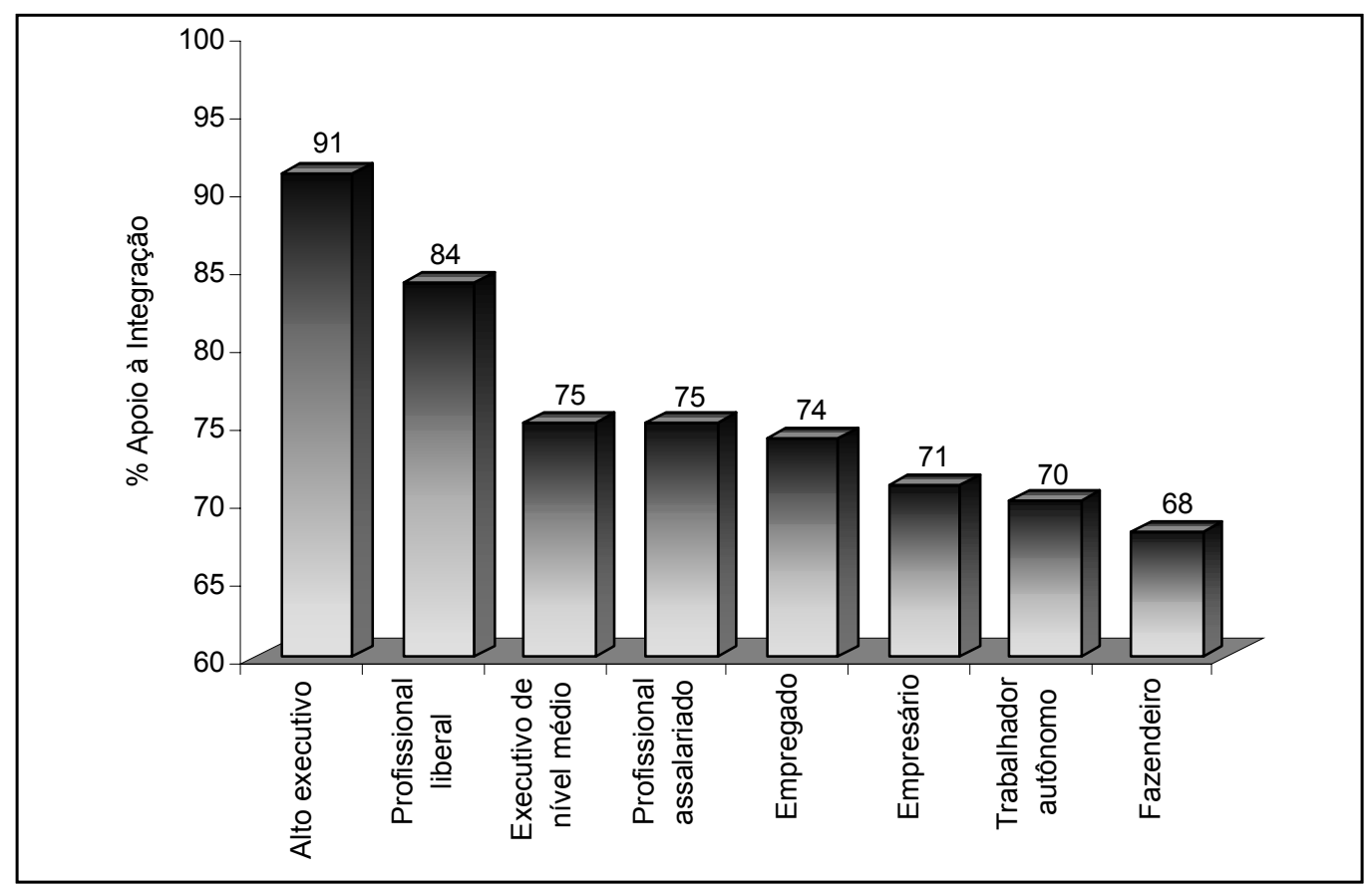

Pesquisa na Europa mostrou que os que têm profissão tendem a apoiar mais a integração que os trabalhadores manuais, o que nos leva a uma análise por ocupação. ${ }^{18}$ A Figura 9 mostra os resultados, que não apresentam surpresas. Uma vez mais vemos que em todas as categorias ocupacionais o apoio médio à integração é positivo. No entanto, entre aqueles com ocupações profissionais de mais alto nível o apoio chega aos $90 \%$, e cai para dois terços entre os fazendeiros.

A última variável socioeconômica ligada ao apoio à integração é a riqueza. Como muitos outros surveys, o Latinobarômetro também não perguntou diretamente sobre os rendimentos, dado que muitos entrevistados se recusam a responder ou dão informações falsas. Obtém-se melhor medida da posição socioeconômica das pessoas perguntando sobre a posse de bens materiais. O Latinobarômetro perguntou sobre 13 desses bens com base nos quais foi criado um índice. ${ }^{19}$ Como se esperava, a riqueza

\footnotetext{
${ }^{18}$ Ver Wessels, op. cit.

${ }^{19}$ Embora os bens incluídos no survey variem muito em custo, de um microondas a um automóvel, os itens da escala não foram ponderados. Foi utilizado um índice somatório, mas, como faltassem informações sobre alguns bens em alguns casos, foram atribuídos valores médios individuais àqueles que tivessem respondido a seis ou mais das 13 questões. Para os que apresentassem maior proporção de falta de informações foi atribuído um código de falta de informação. Os bens eram: TV em cores, vídeo, câmera de vídeo, geladeira, computador, forno de microondas, máquina de lavar, telefone, automóvel, segunda casa ou apartamento, água encanada, água quente e conexão à rede de esgotos.
} 
está positivamente associada ao apoio à integração, ainda que a relação não seja forte ( $r$ $=0,11$; sig. <0,001). Como a riqueza e a educação são fortemente correlacionadas, a relação entre riqueza e apoio à integração se mostra falsa quando se controla a educação. A análise multivariada apresentada na conclusão deste trabalho exclui a riqueza porque ela se torna um preditor insignificante quando a educação é inserida na equação.

\section{O Papel Modelo da União Européia}

As relações entre a América Latina e a Europa variam amplamente de país para país. Em termos gerais, os países do Cone Sul têm dado mais atenção à Europa que os da América Central. Em anos recentes, a União Européia vêm apoiando programas (seminários, palestras, etc.) para popularizar seu modelo de integração regional na América Latina. ${ }^{20}$ Embora não seja possível mostrar uma ligação direta entre esses esforços e a opinião pública, os dados mostram forte relação entre opinião favorável à União Européia e apoio à integração regional latino-americana. Os latino-americanos também deram sua opinião sobre os Estados Unidos na mesma série de questões, e o país ficou significativamente abaixo da União Européia: $58 \%$ dos entrevistados exibiram opinião positiva sobre a União Européia, contra 48\% sobre os EUA. A Figura 10 mostra a relação entre a opinião sobre a União Européia e apoio à integração econômica latinoamericana. Entre os latino-americanos que têm opinião muito negativa sobre a União Européia, apenas um terço apóia a integração na América Latina, enquanto que, entre os que têm uma opinião favorável, mais de $80 \%$ apóiam a integração.

A relação entre opinião sobre a União Européia e o apoio à integração latinoamericana não é apenas um apoio generalizado aos países estrangeiros. Uma análise da opinião sobre os EUA e o apoio à integração revela associação positiva, mas que é extremamente fraca e não confirma o padrão linear da anterior. Existe, claro, o risco envolvido na imitação. Se a União Européia fracassar como unidade de comércio, os latino-americanos poderão compreensivelmente tornar-se mais descrentes do modelo, mas se as coisas continuarem como estão, o modelo europeu parece ser responsável por ajudar a inspirar apoio à integração latino-americana.

\footnotetext{
${ }^{20}$ Para uma revisão dessa literatura ver Simon Françoise e Susan Kaufman Purcell, The Impact of Regional Integration on European-Latin American Relations, in Europe and Latin America in the World Economy, orgs. Simon Francoise e Susan Kaufman Purcell, Boulder, Colorado, Lynne Reinner Publishers, 1995.
} 
FIGURA 10

Opinião sobre a União Européia e Apoio à Integração Econômica na América Latina

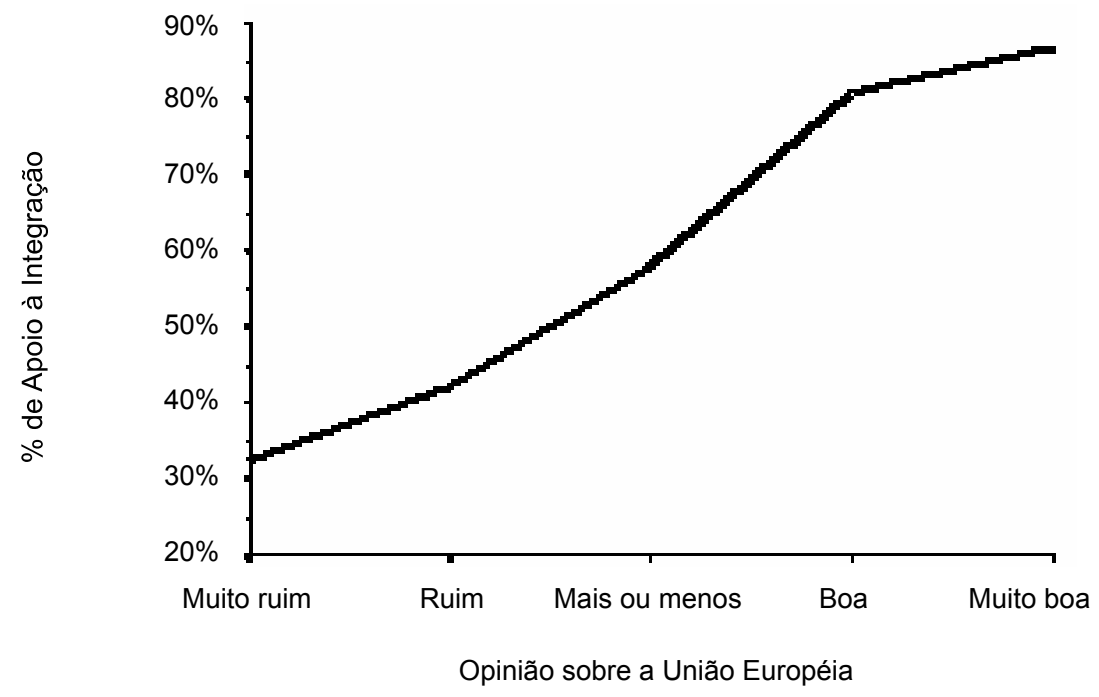

\section{Apoio à Democracia}

Como observado no início deste trabalho, a América Latina é institucionalmente democrática neste momento, uma mudança significativa em relação a décadas anteriores. Também é fato que a América Latina tem caminhado para a integração econômica de maneira mais firme e profunda que no passado. Existe uma associação entre as duas coisas? Ou seja, pode o apoio à democracia traduzir-se em apoio a um modelo econômico que envolve a integração regional? Os dados sugerem uma resposta afirmativa a essa questão.

O Latinobarômetro contém um item freqüentemente utilizado para medir apoio à democracia: "em geral, você diria que está muito satisfeito, satisfeito, não muito satisfeito ou insatisfeito com o modo como a democracia funciona em [preencher com o país]?" $\mathrm{Na}$ América Latina, há uma relação estatisticamente significativa $(<0,001)$ entre a satisfação com a democracia e apoio à integração econômica. O apoio à integração aumenta de aproximadamente dois terços entre aqueles pouco satisfeitos com a democracia para quase $80 \%$ dos que estão satisfeitos com ela. Outro item no survey pergunta: "você estaria disposto a defender a democracia se ela estivesse ameaçada?" Novamente aqui a relação é estatisticamente significativa $(<0,001)$, com três quartos dos dispostos a defender a democracia favoráveis à integração contra dois terços dos que não estão dispostos a defendê-la. 


\section{Atenção Política}

O survey inclui várias questões para medir a atenção política dos entrevistados. Análise de todas elas revela o mesmo padrão: os mais atentos à política apresentam maior apoio à integração. Por exemplo, o survey pergunta sobre audiência a noticiários políticos na TV e no rádio, e sobre leitura das seções políticas dos jornais. Também formula uma questão mais geral sobre a freqüência com que o entrevistado "acompanha as notícias políticas". O padrão dessas medidas é semelhante. Na Figura 11 estão apresentados os resultados para a questão mais geral. O padrão para os homens é forte e linear, de tal modo que menos de $55 \%$ dos que não prestam qualquer atenção à política apóiam a integração, contra mais de $80 \%$ dos que prestam atenção freqüentemente. Entre as mulheres, o padrão é muito menos marcado e chega a mostrar declínio no grupo mais atento.

\section{FIGURA 11}

Atenção às Notícias Políticas e Apoio à Integração Econômica, segundo Gênero

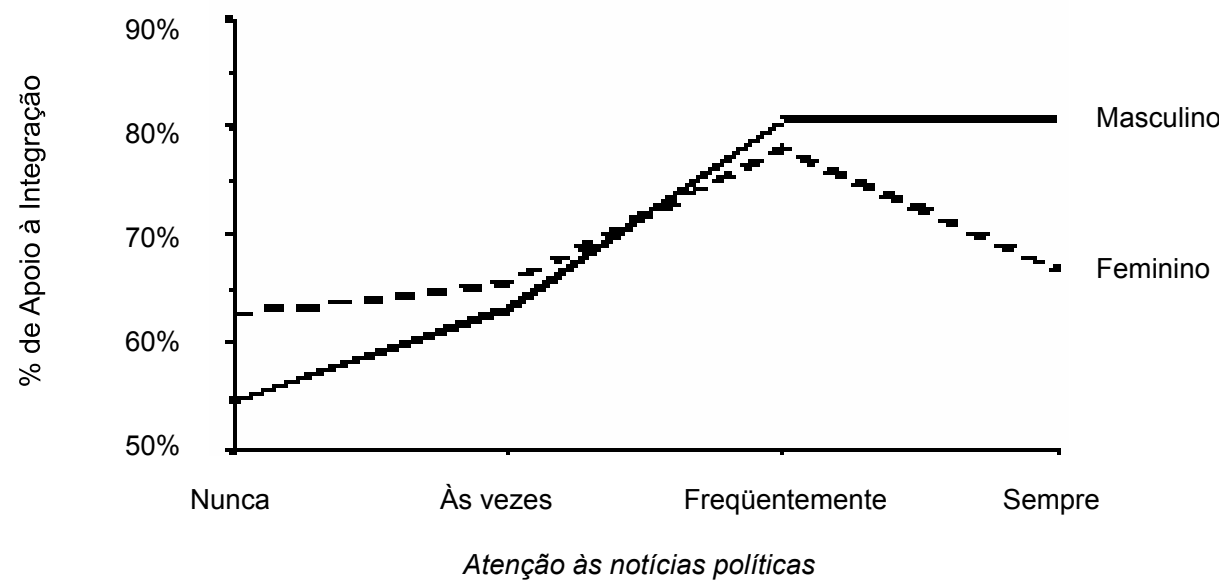




\section{O Modelo Geral de Apoio à Integração Econômica}

Até aqui, o estudo adotou a análise bivariada para que o leitor pudesse visualizar com facilidade as relações entre cada fator e o apoio à integração econômica na América Latina. Como os próprios fatores explicativos são inter-relacionados (p. ex., a educação está positivamente associada com diversas das variáveis discutidas acima), é importante examinar a relação inteira utilizando técnicas multivariadas. Os resultados apresentados a seguir incorporam todas as variáveis discutidas neste trabalho, empregando, como variável dependente, o apoio à integração na América Latina. ${ }^{21}$ A Tabela 3 apresenta os resultados da regressão OLS.

\section{TABELA 3}

Resultados da Regressão OLS

\begin{tabular}{|c|c|c|c|c|c|}
\hline & \multicolumn{2}{|c|}{$\begin{array}{c}\text { Coeficientes } \\
\text { Não estandarizados }\end{array}$} & \multirow{2}{*}{$\begin{array}{c}\text { Coeficientes } \\
\text { estandarizados } \\
\text { Beta }\end{array}$} & \multirow[b]{2}{*}{$\mathrm{t}$} & \multirow[b]{2}{*}{ Sig. } \\
\hline & $\mathrm{B}$ & Erro padrão & & & \\
\hline (Constante) & -20.442 & .688 & & -.29 .730 & .000 \\
\hline Benefícios da integração econômica & .338 & .003 & .226 & 99.066 & .000 \\
\hline Opinião sobre a União Européia & 10.303 & .111 & .213 & 92.941 & .000 \\
\hline Situação econômica & .171 & .004 & .095 & 42.889 & .000 \\
\hline Educação & 2.064 & .603 & .077 & 32.915 & .000 \\
\hline Disposição a defender a democracia & 5.882 & .233 & .055 & 25.426 & .000 \\
\hline Atenção a notícias políticas & 2.685 & .120 & .050 & 22.426 & .000 \\
\hline Satisfação com a democracia & 2.285 & .127 & .039 & 17.991 & .000 \\
\hline Empresário & -6.427 & .409 & -.036 & -15.718 & .000 \\
\hline Estudante & -5.092 & .330 & -.037 & -15.435 & .000 \\
\hline Profissional assalariado & -4.943 & .535 & -.021 & -9.234 & .000 \\
\hline Desempregado & -2.405 & .278 & -.023 & -8.657 & .000 \\
\hline Profissional independente & 4.533 & .654 & .015 & 6.934 & .000 \\
\hline Empregado & -1.623 & .284 & -.014 & -5.717 & .000 \\
\hline Gênero & -.970 & -.209 & -.011 & -4.636 & .000 \\
\hline
\end{tabular}

$R$-quadrado ajustado =0,019, sig. <0,001. Gênero $1=$ homem, $2=$ mulher

\section{Regressão OLS: Preditores do Apoio à Integração Latino-Americana}

Cada uma das variáveis discutidas neste trabalho (exceto a riqueza, como observado acima) é um preditor significativo do apoio à integração na América Latina. Um fator-chave são os benefícios percebidos da integração; quanto maiores os benefícios percebidos, tanto maior o apoio. Há também uma associação positiva entre a opinião dos latino-americanos sobre a União Européia e o apoio à integração. As duas importantes variáveis socioeconômicas e demográficas, educação e gênero, são também significativas, com o valor $t$ mais alto para a educação que para qualquer das outras

21 O Latinobarômetro contém grande número de variáveis e aquelas que pareceram teoricamente apropriadas foram examinadas à luz de suas ligações com o apoio à integração. Este trabalho inclui as que se mantiveram significativas na análise multivariada. A construção de índices para algumas das variáveis, por exemplo, o agrupamento do grande número de questões relacionadas à atenção à mídia, produz resultados ligeiramente diferentes, que não afetam a substância da análise. 
variáveis no modelo. Gênero, porém, tem um valor $t$ muito baixo, se comparado ao da educação. O apoio à democracia (na forma de disposição a defendê-la e satisfação com seu funcionamento) também desempenha papel independente na explicação do apoio à integração. Os mais atentos às notícias políticas apóiam mais a integração. A variável ocupação foi subdividida numa série de variáveis dicotômicas (dummy) de modo a ver mais claramente o efeito dos grandes grupos ocupacionais. Os fazendeiros que, na Figura 9, exibiam o menor nível de apoio à integração foram utilizados como categoria base com a qual as outras foram comparadas. Desempregados e estudantes foram também incluídos como categorias separadas. Como se pode ver a partir dos sinais dos coeficientes na Tabela 3, apenas o status de profissional independente está positivamente associado ao apoio à integração (as categorias executivo de alto nível e executivo médio, que também tinham ligações positivas com o apoio, deixaram de ser significativas depois que outras variáveis foram incluídas na regressão. Por outro lado, os empresários, estudantes, profissionais assalariados, desempregados e empregados, todos tiveram impacto negativo sobre o apoio. Em termos gerais, a ocupação teve apenas um pequeno papel na determinação do apoio, como mostram os valores $t$.

\section{Implicações e Conclusões}

Este trabalho apresenta de várias maneiras um quadro das atitudes populares sobre a integração econômica na América Latina que agradaria aos que apóiam a integração. Com exceção de quatro dos 17 países, dois terços dos entrevistados apóiam a integração; em nove dos 17, três quartos ou mais dos que expressam opiniões a apóiam. Em cada um dos países, a maioria dos que têm opinião apóia a integração. Esses resultados poderiam ser vistos com uma breve observação às proporções apresentadas nos resultados do Latinobarômetro. Mas o melhor deste estudo foram as análises bivariada e multivariada.

Duas variáveis socioeconômicas aparecem como diretamente ligadas ao apoio à integração latino-americana: os benefícios percebidos dos blocos comerciais regionais e a percepção da situação econômica pessoal e nacional. Isso sugere que o sucesso gera o sucesso, e quanto mais a América Latina prosperar com o comércio regional e sua economia florescer, tanto maior seria o apoio à integração regional.

Os latino-americanos também estão atentos à Europa e ao seu processo de integração. Quanto melhor a opinião sobre a integração européia, tanto maior o apoio à integração latino-americana, o que sugere que os esforços da União Européia e de seus países membros para promover os ideais da integração para além de suas fronteiras podem ter um efeito positivo. Como nenhuma pessoa razoável poderia esperar uma navegação completamente suave do processo europeu nos próximos anos, é importante que a União Européia continue a promover seu modelo na América Latina para contrabalançar os inevitáveis desapontamentos. 
As mulheres apóiam menos a integração do que os homens em muitos países da América Latina. Grande parte dessa diferença, porém, é função dos mais baixos níveis educacionais das mulheres, em comparação com os homens. Controlada a educação, o hiato de gênero na opinião se estreita consideravelmente, como mostrou a análise de regressão. Talvez o mais importante, na perspectiva da formulação de políticas, seja que os mais educados e atentos à mídia apóiam fortemente a integração. Como os mais educados são geralmente os politicamente mais ativos na sociedade, os que mais votam e mais fazem demandas a seus representantes, é provável que o apoio popular à integração seja especialmente eficaz em influenciar a formulação de políticas. Ademais, a opinião dos mais educados pode ter um efeito restritivo sobre regimes populistas que, de tempos em tempos, são eleitos na América Latina com base em apelos nacionalistas. Se esses regimes procurarem isolar seus países da integração econômica regional, podem ter que enfrentar oposição popular majoritária, liderada pela mais forte oposição dos mais escolarizados.

Finalmente, é bom ver que a democracia e o apoio à integração estão ligados. Quanto mais estão satisfeitos os latino-americanos com a democracia e quanto mais estão dispostos a defendê-la, maior seu apoio à integração econômica. Se a América Latina continuar em seu recente caminho de crescente democratização, isso implica em que haverá crescente apoio à integração econômica. Pode-se mesmo especular que o apoio à integração econômica pode levar ao apoio à integração política, mas essa esperança já foi manifestada pelos primeiros teóricos da integração econômica e não têm sido confirmadas. $^{22} \quad$ O nacionalismo na América Latina tem sido muitas vezes subestimado por causa da baixa freqüência de guerras na região neste século. Talvez o nacionalismo desapareça juntamente com o militarismo e as ditaduras do passado, mas os dados utilizados não permitem explorar essa possibilidade. Por enquanto, os que apóiam a integração na América Latina terão que se contentar com o quadro otimista aqui apresentado, sem saltar à injustificada conclusão de que cedo veremos a emergência dos "Estados Unidos da América Latina".

Tradução do original em inglês de Plínio de Souza Dentzien

\footnotetext{
${ }^{22}$ Um dos primeiros estudos a mostrar a descontinuidade entre a integração econômica e a política foi Mitchell A. Seligson, "Transactions and Community Formation: Fifteen Years of Growth and Stagnation in Central America", Journal of Common Market Studies 11 1973: 173-190.
} 